\title{
Nursing Students Perception of E-learning during COVID-19 Pandemic; A Literature Review
}

\author{
Mohammad R. AlOsta ${ }^{1}$, Inaam A. Khalaf ${ }^{2}$ \\ ${ }^{1}$ RN, PhD, Specialty Hospital, Amman, Jordan, ${ }^{2}$ Professor, School of Nursing, the University of Jordan, Amman, \\ Jordan
}

\begin{abstract}
Background: E-learning has expanded recently in response to the social distance measures during COVID-19 pandemic. A part of the learning process is evaluating its effectiveness and impact on learners.

Aim: to examine nursing students' perceptions of e-learning during COVID-19 pandemic.

Methods: A literature search to identify publications on perceptions of e-learning was conducted via three databases.

Conclusion: Sixty five articles were included and reviewed. The articles addressed the following: (1) benefits of e-learning, (2) drawbacks and challenges (3) Students' interaction, (4) e-learning environment (5) students' engagement and satisfaction, (6) e-learning during COVID-19 pandemic, and (7) Clinical training during COVID-19 pandemic. Shifting to E-learning during the COVID-19 pandemic has many benefits that positively impact student health status and learning outcome, although it has several drawbacks and barriers that can affect the learning process quality. Finally, implementing e-learning is not an easy task; higher education institutions should consider several factors to provide the students with an efficient learning process.
\end{abstract}

Keywords: e-learning, COVID-19 pandemic, learning environment, nursing students, students satisfaction, and students engagement.

\section{Introduction}

During communicable disease outbreaks social distancing is recommended to stop the infection cycle by increasing the distance between people and decreasing the frequency of contacts ${ }^{1}$. Pandemics drives countries to have proactive plans to find an alternative to the traditional education system ${ }^{2}$. For instance, more than 300 million students worldwide have their education interrupted by the COVID-19 pandemic spread ${ }^{3}$.

\section{Corresponding author}

Mohammad R. AlOsta, RN, PhD (C)

Specialty Hospital, Amman, Jordan

mro1984@yahoo.com

ORCID ID: https://orcid.org/0000-0003-1710-3391

Tel: 00962782341306
E-learning has recently been acknowledged in several educational research studies as an emerging education method across different contexts and domains. A part of the learning process is evaluating its effectiveness and impact on learners. The evaluation of e-learning focuses on learners' outcomes, students' and instructors' attitudes, and satisfaction ${ }^{4,5}$. The current review aimed to examine nursing students' perceptions of e-learning during COVID-19 pandemic.

\section{Methods of Literature Search}

A literature search to identify publications on perceptions of the education environment, engagement level, satisfaction levels with e-learning during pandemics was conducted via PubMed, CINAHL, SAGE journals, and Google scholar. The researcher used 
different keyword combinations to identify research articles and systematic reviews related to e-learning. Keywords included: "online learning", "e-learning", "COVID-19", "pandemic", "learning environment", "education outcomes", "nursing students", "students satisfaction", and "students engagement".

The retrieved articles were included if they met the following criteria: (1) research reports or literature review (2) addressed e-learning; (3) full-text publications written in English.

\section{Results and Discussion}

A total of(937) articles were extracted during the first search, including research articles, systematic reviews, academic dissertations, and conference abstracts. The duplicate papers were eliminated, and (564) articles were identified; of these (143) records were excluded because they did not address e-learning, were not written in English or were not available as full text. Then, the titles of (421) articles were screened. Of these (153) articles were identified as irrelevant and excluded after reading the title. Then, the abstracts of the (268) articles were screened. Of these, (187) articles were identified as irrelevant and were excluded, and (81) articles met the criteria and were reviewed in full and evaluated for eligibility. Of these, (56) final articles were selected and included in the review.

\section{Literature Findings}

After an in-depth review of the included studies, results were summarized according to the following headings:(1) benefits of e-learning, (2) drawbacks and challenges (3) Students' interaction, (4) e-learning environment (5) students' engagement and satisfaction, (6) e-learning during COVID-19 pandemic, and (7) Clinical training during COVID-19 pandemic.

\section{Benefits of E-learning}

The focus on social distancing promoted the market for e-learning courses to ensure the continuity of learning for higher education institutions ${ }^{6}$.E-learning has been known as a cost-effective learning solution that enhances learning through various technical methods such as audio chatting, video conferencing, and online discussion ${ }^{7}$.

E-learning can positively influence the teachinglearning process by providing educational opportunities tonursing students to achieve their academic objectives and building sustainable academic and professional development opportunities ${ }^{8}$. Moreover, before integrating e-learning, considerable geographical barriers have influenced students' access to education, where many learners had to travel to campuses ${ }^{9}$.

In the same assertion, constructive innovations in internet and telecommunications technology eliminated socioeconomic, geographic, financial, educational, and personal barriers. It provides convenience and adaptability that traditional face-to-face classes cannot offer, particularly essential for students who balance work, school, and family ${ }^{10}$. E-learning is a method designed specifically for students who want to take advantage of accessing materials at any time and any place, the opportunity to reach a larger mass at the same time with content uniformity ${ }^{11,12}$. Bolliger and Halupa ${ }^{13}$ recruited 667 students enrolled in online courses at three private universities in the United States of America (USA). Results indicated that students were highly engaged; most of them reported being organized, wanted to learn the material, and apply it to their lives. On the other hand, theydid not feel a high level of transactional distance; they described the instructor as being helpful, paying attention to them, and providing appropriate feedback. Another significant finding was that students were satisfied with their outcomes (learning and achievement of learning goals).

\section{Drawbacks and Challenges}

One of the main drawbacks of e-learning is the level of interaction. The design of online training does not enable teachers to interpret significant non-verbal signs that signify comprehension. In comparison, faceto-face training helps the teacher evaluate students' understanding using non-verbal actions, then improve accordingly ${ }^{14}$. 
Researchers were concerned with several issues in e-learning, including the sense of isolation and separation from peers and teachers ${ }^{15}$. Others were concerned with faculty members' inability to provide individualized instructions to cover the learning needs, the frequent technical problems ${ }^{16}$. Other barriers include additional time needed for course preparation by the instructors, frequent one-to-one communication between faculty and student through email or phone calls, and insufficient technical expertise to design the educational course and content ${ }^{17}$.

Higher education institutions worldwide face several challenges to implement e-learning, such as lack of awareness, resources, training, incentives, and management support for e-learning; a low number of enrolled students; and inadequate faculty qualifications ${ }^{18,19}$. In addition to these challenges, distance learning in the Middle East is faced with poor internet dissemination, low public appreciation, and a lack of online educational databases ${ }^{20}$.

Several studies have been conducted in Jordan to identify these barriers. A research study described the reasons behind the delays in using e-learning methods. A questionnaire was distributed to both students and educators at several Jordanian universities revealed acceptance of both online and conventional learning methods. However, insufficient infrastructure and a lack of sufficient support from government and higher education management impeded its advancement ${ }^{21}$. Another survey study recruited 400 students randomly from Jerash Universityrevealed that infrastructure is an enormous challenge that obstructs online learning effective utilization. Besides, they reported that students' perceived challenges while using online learning differ based on gender and studying year level, in favor of females and students of the first year ${ }^{22}$.

A study assessed the degree of academic staff preparedness to introduce e-learning at Jordanian universities. The researcher incorporated quantitative and qualitative approaches to collect data from 367 academic staff. The questionnaire discussed psychological, administrative, technical, affective, and change factors. The participants showed a high level of readiness to incorporate e-learning within their programs. However, they addressed several challenges, such as technology hindrances and lack of e-learning tools ${ }^{23}$.

\section{Students' Interaction}

Interaction is considered an essential component of learning environments that guides distance learners; it is persuaded by motivation and achievement. It could lead to a more productive experience of distance learning If students fail to recognize their presence, potential issues may arise, such as a high drop-out rate, low achievement, and low satisfaction with learning ${ }^{24}$, and failure to build a community of learning and connect with other learners ${ }^{25}$.

Moore $^{26}$ recognized three different types of interaction during online courses: (1) student-to-student, (2) student-to-instructor, and (3) student-to-material. These interactions have been found to help online learners become more engaged and interested in their courses. These different forms of interaction have been found to provide students with various opportunities to control and manage their own learning ${ }^{27}$.

Social interaction through emotional expression, open communication, and group cohesion can be connected to emotional engagement, whereas lower levels of interaction can trigger discomfort and negatively affect affective learning ${ }^{28}$. This was supported by a recent study aimed to understand the factors that contribute to students' involvement and predict satisfaction among 439 undergraduate and post-graduate students enrolled in online courses in the United Arab Emirates (UAE). The study revealed that clear communication, learning community, and time management skills are indicators of students' satisfaction, online achievement, and retention ${ }^{29}$.

\section{E-learning Environment}

Student's perception of learning environment is an essential factor for successful e-learning. The learning 
environment was examined by $\mathrm{Kirmizi}^{30}$ using six psycho-social scales concerning instructor support, active learning, personal relevance, student interaction and collaboration, authentic learning, and student autonomy. A moderate level of correlation between the study variables was reported. Instructor support, personal relevance, and authentic learningwere predictors of student satisfaction, while authentic learning was the only strong predictor of academic achievement ${ }^{30}$.

Another research examined the students' perceptions of the learning environment, engagement, previous academic achievement in relation to learning outcomes. The study has recruited 2,616 seniors who are working full-time at a university in Mainland China. The research findings showed that prior academic achievement and students' perceptions of e-learning environment indirectly affected students' engagement and directly affected their learning outcomes ${ }^{31}$.

\section{Students' Engagementand Satisfaction}

Engagement is one of the main factors improving learning performance ${ }^{32}$. Also, it is considered one of the predictors for student satisfaction. Previous studies showed that engagement in online learning environments has a major impact on satisfaction ${ }^{33}$. Learners who engage in their education process mayexperience more satisfaction.Students' engagement influences the level of their learning outcomes, cognitive development, and the quality of education ${ }^{34}$.

Learner engagement is a process variable that predicts learning outcomes. The student engagement was distinguished from its antecedents and consequences ${ }^{35}$. Engagement is a process that is affected by the antecedents (e.g. student context, encouragement, perception) and affects the consequences (e.g. satisfaction and grades). Other researchers also proposed the mediating impact of student engagement on the relationship between the personal and contextual factors with learning outcomes ${ }^{36}$.

Moreover, there are several effective factors related to student engagement, including personality, motivation, attitude, effort, and self-confidence.
Teachers can prepare lessons and events more efficiently by determining the degree of student engagement, enabling them to be more active participants in their learning and coursework ${ }^{37}$. Researchers from the University of California randomized 148 students into groups to attend one of eight video styles (traditional classroom, learning glass, weatherman, pen tablet, slides on/off, talking head, demo, and interview) that were designed to deliver standardized content ${ }^{38}$. Despite their equal learning outcomes, students preferred certain video styles, mainly if they were engaging and evoked positive affective responses. For instance, the 'learning glass' and the 'demo' ranked highest for perceived effectiveness, while the 'interview' ranked the lowest ${ }^{38}$.

A survey-based study examined students' perception of different engagement strategies used in online courses. One hundred fifty-five students were recruited from eight universities that used online learning in the USA. The survey consisted of three categories, including learner-to-learner, learner-to-instructor, and learner-to-content engagement. The learner-to-learner category was rated the most beneficial strategy through collaborative work using online communication tools; the learner-to-instructor category seemed to be the most valued strategy, it was rated most beneficial by sending regular announcements, email reminders, and grading for all assignments. Lastly, the learner-content category was the most beneficial while working on realworld projects and having discussions with structured or guiding questions ${ }^{39}$.

One of the key predictors of the quality and efficacy of online courses is student satisfaction ${ }^{40}$. Satisfaction refers to how individuals view their learning experiences, and it is a fundamental link in student performance along with their engagement and achievement ${ }^{41}$. A systematic review was conducted to identify factors affecting the students' and instructors' satisfaction with distance learning. The review revealed that most studies reported the satisfaction as a mediator between 11 factors, including (system quality, information quality attitude, social influence, confirmation, usefulness, ease of use, attainment value, intrinsic value, utility value, and task- 
technology fit) and students decisions to continue using e-learning approach as a learning method ${ }^{42}$.

In the same context, several studies examined the relationship between learners' satisfaction and their interactions with the educational content, instructors, and other learners during the e-learning approach. For instance, Alqurashi ${ }^{43}$ collected data from 167 participants from a private non-profit university in Western Pennsylvania. He found that the most significant predictor of student satisfaction is learner-content interaction, which supports previous results of other studies in addition to learner-instructor interaction ${ }^{44}$. On the other hand, learner-learner interaction was not a predictive variable ${ }^{43}$.

Furthermore, a wide variety of research has focused on factors influencing learner satisfaction; Eom et al. ${ }^{40}$ concluded that the course structure, input from the instructor, self-motivation, style of learning, engagement, and facilitation of the teacher significantly affected student satisfaction. However, perceived learning outcomes were substantially influenced only by teacher feedback and learning style.

In the same line, the satisfaction levels with e-learning among undergraduate students at Turkish private universities were examined. The study found that only $37 \%$ of the participants attended an orientation course for e-learning, yet the majority perceived e-learning as an effective way of learning; more specifically, they were more satisfied with the technical support. Another significant finding was that students' achievement did not affect their enrollment in e-learning; however, it affected their overall program evaluation ${ }^{45}$.

\section{E-learning during COVID-19 Pandemic}

There has been an increased reliance on using technologies during the COVID-19 outbreak. In order to connect, entertain, and gather knowledge, people worldwide depend heavily on online platforms. Similarly, online technology is now used by the education system to conduct learning practices ${ }^{46}$. A descriptive cross-sectional study was conducted to assess the effect of e-learning among nursing students and teachers during the COVID-19 pandemic. Data was gathered through online surveys from nursing faculties and students recruited from 13 different nursing colleges in Nepal. The participants viewed distance learning as a good opportunity to continue education. However, almost half of the teachers and more than half of the students reported facing problems, such as electricity and internet disconnection. They demanded solving these main issues and taking factors influencing e-learning into account to make the education system more efficient ${ }^{47}$.

According to Diab and Elgahsh ${ }^{48}$, almost $61.6 \%$ of students had negative attitudes towards distance learning; these attitudes were linked to the barriers facing nursing students. These findings were concluded by a descriptive correlational study conducted in the Faculty of Nursing of Menoufia University in Egypt during the COVID-19 pandemic. The data was collected from 627 students recruited using a stratified random sampling technique. The participants completed a questionnaire that comprised a scale measuring the attitude towards e-learning and the obstacles to its use. Another important finding of the study was reporting the infrastructure, technology, and technical management support, and instructors' characteristics as the most prevalent barriers to distance learning.

Further, most studies conducted on e-learning in Jordan examined the obstacles to using e-learning during the COVID-19 pandemic. The first study used a cross-sectional design to investigate the obstacles to using online tools during the COVID-19 pandemic for undergraduate health sciences students.A total of 1,210 participants have completed the online survey questionnaire. Most of them agreed that online courses provide more time for reading and homework than the traditional learning method and that they felt comfortable communicating regularly with their classmates and teachers. Moreover, students listed geographical areas, lack of previous experience in using online resources, andlack of previous experience using online tools as the key obstacle to online education ${ }^{49}$. 
Clinical Training during COVID-19 Pandemic

During the COVID-19 pandemic, the health sciences schools in Croatia switched to e-learning. A cross-sectional study recruited 2,520 students from 9 health sciences schools ${ }^{50}$. Generally, the students were satisfied with the e-learning. The majority of them (65\%) showed higher motivation to attend e-learning. On the other hand, less than half of them felt deprived of adequate clinical training and worried about that gap in their education. The students recommended combining traditional classroom and e-learning in future semesters.

In the same context, similar findings were reported by nursing students in Sri Lanka ${ }^{51}$. Nursing students, who identified the clinical training as an integral part of nursing curricula, revealed that COVID-19 negatively affected their ability to conduct accurate clinical assessments and standard procedures. The students highlighted that the limited resources in Sri Lanka hindered the appropriate utilization of online education; they suggested that higher education institutions must provide material support for students to support their training.

A qualitative study was conducted to discover the learning experiences and the expectations about the abrupt changes in the education of nursing students enrolled in Bachelor's and Master's degrees of two public Spanish universities ${ }^{52}$. In terms of clinical training, the students emphasized its importance for the completion of a nursing certificate. Some students mentioned that they prefer to postpone their graduation to get a better chance of clinical training; others linked it with the acquisition of competencies that prepare them for better job opportunities. Similar findings were reported by a cross-sectional study that aimed to evaluate the impact of COVID-19 on post-graduate orthopedic students in India ${ }^{53}$. The study revealed that more than half of the students denied having clinical classes during the COVID crisis; they also confirmed that this affected their competence that may interfere with their work performance later.
Another qualitative study ${ }^{54}$ aimed to explore the students' experience and how they perceive the global pandemic. Most students recognized the importance of clinical education; however, they expressed their concerns and fears of the clinical settings and linked it with getting infected, even after the pandemic had ceased.

Konrad et al. ${ }^{55}$ examined the strategies used to support nursing students' clinical competency during the COVID-19 pandemic in the USA. They found that spending more time with students, using interactive learning activities, simulation training, and clinical reasoning scenarios improved the assessment of learning objectives, competencies, and students' clinical reasoning abilities, despite the lack of traditional direct patient care.

At the national level, a descriptive qualitative design was used to investigate undergraduate nursing students' experiences after a sudden shift to online learning due to the COVID-19 pandemic. Data were collected through two online focus group discussions from Eighteen students recruited purposively from two Jordanian universities. Four themes emerged from the data: the need for social and technical support; experience of helplessness, burdens, and burnout; the deficiency of online in fulfilling clinical courses' outcomes; and the propensity to consider online as a positive opportunity. They concluded that online learning was a beneficial but stressful experience that challenged their clinical training 56 .

\section{Conclusion}

In summary, the current review aimed to examine the relationship between e-learning and nursing students' perceptions of the education environment, their engagement, and satisfaction levels with e-learning during the COVID-19 pandemic. Shifting to E-learning during the COVID-19 pandemic has many benefits that positively impact student health status and learning outcome, although it has several drawbacks and barriers that can affect the learning process quality. Moreover, implementing e-learning is not an easy task; higher 
education institutions should consider several factors to provide the students with an efficient learning process.

Ethical Clearance: Taken from the School of Nursing / University of Jordan IRB commitee.

Source of Funding: None

\section{Conflict of Interest:Nil}

\section{References}

1. Hensley L. Social distancing is out, physical distancing is in - here's how to do it. Global NewsCanada. https://globalnews.ca/news/6717166/ what-is-physical-distancing/. Published 2020.

2. Uscher-Pines L, Schwartz HL, Ahmed F, et al. School practices to promote social distancing in K-12 schools: Review of influenza pandemic policies and practices. BMC Public Health. 2018;18(1):1-13.

3. UNESCO. Impact of the 2019-20 coronavirus pandemic on education. In: COVID-19 Educational Disruption and Response. ; 2020. https:// en.unesco.org/themes/education-emergencies/ c\%0Aoronavirus-school-closures.

4. Bayrak M, Aydemir M, Karaman S. An Investigation of the Learning Styles and the Satisfaction Levels of the Distance Education Students. Cukurova Univ Fac Educ J. 2017;46(1):231-263.

5. Hu PJH, Hui W. Examining the role of learning engagement in technology-mediated learning and its effects on learning effectiveness and satisfaction. Decis Support Syst. 2012;53(4):782-792.

6. Kozan K, Richardson JC. Interrelationships between and among social, teaching, and cognitive presence. Internet High Educ. 2014;21:68-73.

7. Odit-Dookhan K. Attitude Towards E-Learning: the Case of Mauritian Students in Public Teis. PEOPLE Int J Soc Sci. 2018;4(3):628-643.

8. Schmitt U. Redefining knowledge management education with the support of personal knowledge management devices. Smart Educ e-Learning,. 2016;59(June 2016):515-525.

9. Bebetsos E. Prediction of participation of undergraduate university students in a music and dance master's degree program. Int $J$ Instr. 2015;8(2):165-176.

10. Arasaratnam-Smith LA, Northcote M. Community
Medico-legal Update, October-December 2021, Vol.21, No. 4275

in online higher education: Challenges and opportunities. Electron $J$ e-Learning. 2017;15(2):188-198.

11. Chang V. Review and discussion: E-learning for academia and industry. Int $J$ Inf Manage. 2016;36(3):476-485.

12. Gökmen ÖF, Uysal M, Yaşar H, Kirksekiz A, Güvendi GM, Horzum MB. Methodological trends of the distance education theses published in Turkey from 2005 to 2014: A content analysis. Egit ve Bilim. 2017;42(189):1-25.

13. Bolliger DU, Halupa C. Online student perceptions of engagement, transactional distance, and outcomes. Distance Educ. 2018;39(3):299-316.

14. Berenson R, Boyles G, Weaver A. emotional intelligence as a predictor. Int Rev Res Open Distance Learn. 2008;9(2).

15. Young S. Student Views of Effective Online Teaching in Higher Education. Int $J$ Phytoremediation. 2006;21(1):65-77.

16. Parker EB, Howland LC. Strategies to manage the time demands of online teaching. Nurse Educ. 2006;31(6):270-274.

17. Cook DA. Web-based learning: Pros, cons and controversies. Clin Med $J R$ Coll Physicians London. 2007;7(1):37-42.

18. Kentnor H. Digital Commons @ DU Sturm College of Law : Faculty Scholarship Distance Education and the Evolution of Online Learning in the United States. 2015;17(1):22-34.

19. Harvey C, Eshleman K, Koo K, Smith KG, Paradise CJ, Campbell AM. Encouragement for faculty to implement Vision and change. CBE Life Sci Educ. 2016;15(4):1-8.

20. Palvia S, Aeron $\mathrm{P}$, Gupta $\mathrm{P}$, et al. Online Education: Worldwide Status, Challenges, Trends, and Implications. J Glob Inf Technol Manag. 2018;21(4):233-241.

21. Mashhour A, Saleh Z. Evaluating e-learning in jordanian institutions: Why is it Lagging? $Q$ Rev Distance Educ. 2010;11(4):269-279. http://search. ebscohost.com/login.aspx?direct $=$ true $\& \mathrm{db}=\mathrm{aph} \&$ $\mathrm{AN}=60145269 \&$ site $=$ ehost-live.

22. Aljaraideh Y, Al Bataineh K. Jordanian Students' Barriers of Utilizing Online Learning: A Survey Study. Int Educ Stud. 2019;12(5):99.

23. Qazaq MNA. A Study on Readiness and 
Implementation of E-Learning Among Academic Staff at Jordanian Institutions of Higher Education. 2012. http://etd.uum.edu.my/2975/3/Mahmoud_ Nayif_Ali_Qazaq.pdf.

24. Robb CA, Sutton J. The importance of social presence and motivation in distance learning. $J$ Technol Manag Appl Eng. 2014;31(2):1-10.

25. Sung E, Mayer RE. When graphics improve liking but not learning from online lessons. Comput Human Behav. 2012;28(5):1618-1625.

26. Moore MG. Three types of interaction. Am $J$ Distance Educ. 1989;3(2):1-7.

27. Gikandi JW, Morrow D, Davis NE. Online formative assessment in higher education: A review of the literature. Comput Educ. 2011;57(4):23332351 .

28. Wei CW, Chen NS, Kinshuk. A model for social presence in online classrooms. Educ Technol Res Dev. 2012;60(3):529-545.

29. Alsrehan HS. Factors influencing education and e-learning technology in UAE universities as a predictor of community satisfaction. Proc - 2019 Int Arab Conf Inf Technol ACIT 2019. 2019:150158.

30. Kirmizi Ö. A study on the predictors of success and satisfaction in an online higher education program in Turkey. Int J Educ. 2014;6(4):26.

31. Guo J. Building bridges to student learning: Perceptions of the learning environment, engagement, and learning outcomes among Chinese undergraduates. Stud Educ Eval. 2018;59(July):195-208.

32. Dixson MD. Measuring student engagement in the online course: the Online Student Engagement scale (OSE).(Section II: Faculty Attitudes and Student Engagement)(Report). Online Learn $J$. 2015;19(4):143.

33. Bitzer $\mathrm{P}$, Janson A. Towards a holistic understanding of technology mediated learning services - A stateof-the-art analysis. ECIS 2014 Proc - 22nd Eur Conf Inf Syst. 2014;(2014).

34. Ma J, Han X, Yang J, Cheng J. Examining the necessary condition for engagement in an online learning environment based on learning analytics approach: The role of the instructor. Internet High Educ. 2015;24:26-34.

35. Kahu ER. Framing student engagement in higher education. Stud High Educ. 2013;38(5):758-773.

36. Zusho A. Toward an Integrated Model of Student Learning in the College Classroom. Educ Psychol Rev. 2017;29(2):301-324.

37. Mandernach BJ, Donnelli-Sallee E, Dailey-Hebert A. Assessing Course Student Engagement. Promot Student Engag Vol 1 Programs, Tech Oppor. 2011:277-281.

38. Choe RC, Scuric Z, Eshkol E, et al. Student satisfaction and learning outcomes in asynchronous online lecture videos. CBE Life Sci Educ. 2019;18(4):1-14.

39. Martin F, Bolliger DU. Engagement matters: Student perceptions on the importance of engagement strategies in the online learning environment. Online Learn J. 2018;22(1):205-222.

40. Eom SB, Ashill N. The Determinants of Students' Perceived Learning Outcomes and Satisfaction in University Online Education: An Update*. Decis Sci J Innov Educ. 2016;14(2):185-215.

41. Sahin I, Shelley M. Considering students' perceptions: The distance education student satisfaction model. Educ Technol Soc. 2008;11(3):216-223.

42. Al-Samarraie H, Teng BK, Alzahrani AI, Alalwan N. E-learning continuance satisfaction in higher education: a unified perspective from instructors and students. Stud High Educ. 2018;43(11):20032019.

43. Alqurashi E. Predicting student satisfaction and perceived learning within online learning environments. Distance Educ. 2019;40(1):133148.

44. Kuo YC, Walker AE, Schroder KEE, Belland BR. Interaction, Internet self-efficacy, and self-regulated learning as predictors of student satisfaction in online education courses. Internet High Educ. 2014;20:35-50.

45. Caliskan S, Suzek S, Ozcan D. Determining student satisfaction in distance education courses. Procedia Comput Sci. 2017;120:529-538.

46. Alhumaid K, Ali S, Waheed A, Zahid E, Habes M. COVID-19 \& Elearning : Perceptions \& Attitudes Of Teachers Towards E- Learning Acceptancein The Developing Countries. Multicult Educ. 2020;6(2):100-115.

47. Subedi S, Nayaju S, Subedi S, Shah SK, Shah JM. 
Impact of E-learning during COVID-19 Pandemic among Nursing Students and Teachers of Nepal. Int J Sci Healthc Res. 2020;5(September):68. www. ijshr.com.

48. Mohamed Abd El-Hamed Diab G, Fouad Elgahsh N. E-learning During COVID-19 Pandemic: Obstacles Faced Nursing Students and Its Effect on Their Attitudes While Applying It. Am J Nurs Sci. 2020;9(4):300.

49. Muflih S, Abuhammad S, Karasneh R, Al-Azzam S, Alzoubi K, Muflih M. Online Education for Undergraduate Health Professional Education during the COVID-19 Pandemic: Attitudes, Barriers, and Ethical Issues. Res Sq. 2020:1-17.

50. Puljak L, Čivljak M, Haramina A, et al. Attitudes and concerns of undergraduate university health sciences students in Croatia regarding complete switch to e-learning during COVID-19 pandemic: a survey. BMC Med Educ. 2020;20(1):1-11.

51. Ilankoon IMPS, Kisokanth G, Warnakulasuriya SSP. COVID-19: Impact on undergraduate nursing education in Sri Lanka. J Public health Res. 2020;9(s1):1-3.
52. Ramos-Morcillo AJ, Leal-Costa C, Moral-García JE, Ruzafa-Martínez M. Experiences of nursing students during the abrupt change from face-toface to e-learning education during the first month of confinement due to COVID-19 in Spain. Int $J$ Environ Res Public Health. 2020;17(15):1-15.

53. Upadhyaya GK, Jain VK, Iyengar KP, Patralekh MK, Vaish A. Impact of COVID-19 on postgraduate orthopaedic training in Delhi-NCR. J Clin Orthop Trauma. 2020;11:S687-S695.

54. Lovrić R, Farčić N, Mikšić Š, Včev A. Studying during the COVID-19 pandemic: A qualitative inductive content analysis of nursing students' perceptions and experiences. Educ Sci. 2020;10(7):1-18.

55. Konrad S, Fitzgerald A, Deckers C. Nursing fundamentals - supporting clinical competency online during the COVID-19 pandemic. Teach Learn Nurs. 2021;16(1):53-56.

56. Suliman WA, Abu-moghli FA, Khalaf I, Zumot AF. Nurse Education Today Experiences of nursing students under the unprecedented abrupt online learning format forced by the national curfew due to COVID-19 : A qualitative research study. Nurse Educ Today. 2021;100(February):104829. 